\title{
Identifying Factors of Indian Health System and Their Influence for Providing Good Customer Care
}

\author{
Meenakshi Sood, Chitkara School of Health Sciences, Chitkara University, Punjab, India \\ Arun Aggarwal, Chitkara University, Punjab, India \\ (iD) https://orcid.org/0000-0003-3986-188X \\ Sahil Gupta, IMS Ghaziabad University Courses Campus, India \\ (iD) https://orcid.org/0000-0003-3342-5382
}

Sanjay Rastogi, Indian Institute of Foreign Trade, New Delhi, India

\begin{abstract}
Customer relationship management is important for any service industry as a satisfied customer is likely to remain loyal and spread publicity, thereby ensuring profits to the organizations. Healthcare is an important and fast-growing service industry in which the patient is the customer, and maintaining good relationship with them is highly profitable. Good customer relationship comes from an understanding of patients' expectations and what factors lead to patient satisfaction. WHO in its report in 2000 introduced the concept-responsiveness, which deals with meeting the universal, legitimate expectations of the patients. This study identifies factors related to patients' expectations, satisfaction, and hence, good customer relations in Indian health system. Structural equation modelling was used to measure the influence of the factors suggested. The results show significant influence of patient expectations on customer relationship.
\end{abstract}

\section{KEYWORDS}

Customer Relationship, Hospitals, Patient's Expectations, Patient's Satisfaction, Responsiveness

\section{INTRODUCTION}

The service sector is probably the fastest growing sector. The impact of the service industry on the economy of a country is huge. Healthcare and Hospitals which are organizations directly serving the patients are an important part of the service industry. In India, the healthcare sector is one of the largest service sectors in terms of employment as well as revenue. The sector includes hospitals, clinics, laboratories, diagnostic centres, telemedicine, outsourcing, medical equipment, and devices. The healthcare delivery system has two main categories- public and private. The public sector is controlled by the government and it mainly consists of primary healthcare centres (PHCs). There are very few secondary and tertiary care hospitals in the public sector. On the other hand, the private sector provides most of the secondary, tertiary and quart nary care. Both the public, as well as the private sector, are growing at a brisk pace and providing good services to the patient.

DOI: 10.4018/IJHISI.20211001.oa13

This article published as an Open Access article distributed under the terms of the Creative Commons Attribution License (http://creativecommons.org/licenses/by/4.0/) which permits unrestricted use, distribution, and production in any medium, provided the author of the original work and original publication source are properly credited. 
In 2012, India had only 0.7 physicians per 1000 population, well below the OECD average of 3.2 and there were 1.1 nurses per 1000 population in India also much lower than the average of 8.8 in OECD countries. About $75 \%$ of children in India were vaccinated against Diphtheria, Tetanus, and Pertussis (DTP) and measles in 2012, less than the coverage in most OECD countries which is close to $100 \%$ (IBEF, 2017). Various researchers in the past, Owens, and Batchelor (1996) and Sitzia and Wood (1997), have suggested that the term 'consumer' should be used for the patient as the user is not passive and dependent. Carr-Hill (1992) suggested the use of term users rather than the customer as a consumer denotes a group of individuals who can safeguard their rights (OECD, 2014). Due to increasing consumerism and wide choices available, patients' expectations have changed over time. From the health system, consumers expect that it should treat them with dignity along with making and keeping them healthy, allow them to make decisions about their treatment, provide them clear information with their health care providers and ensure confidentiality of their medical records. These actions of the health system are collectively put as one group within responsiveness, respect for persons (De Silva \& Valentine, 2000; Gostin, Hodge, Valentine, \&Nygren-Krug, 2002; Murray $\&$ Frenk, 2000). Consumers also expect access to social support, prompt attention, choice of care provider and essential amenities of adequate quality. These expectations form another group called client orientation (Murray \&Frenk, 1999). Put together respect for persons and client orientation form -Responsiveness, a concept which came up in Annual report of the World Health Organization in 2000 (WHO Report 2000). Responsiveness is concerned about meeting the universal, legitimate non-health expectations of patients.

The seven elements of responsiveness (WHO Report 2000) as defined by WHO are:

a) Dignity- the right of individuals to be treated as persons and not merely as patients and hence the right to be treated with respect. This also includes other issues related to the safeguarding of a patient's human rights (for example the right not to be put in isolation if suffering from a communicable disease).

b) Autonomy- freedom to deciding between different treatments available, diagnostic testing and care options, even the decision to refuse treatment, if of sound mind.

c) Confidentiality- safeguarding privacy in the background of privileged communication and medical records.

d) Prompt attention- It has two aspects. Access, where the patient gains care speedily at conveniently located health care units. It is important, not only because it would improve health outcomes (which would be captured under the measurement of health), but also because the existence of such facilities at a close place would improve individuals' confidence. Second, aspect is welfare enhancement by minimizing the waiting time for consultation, treatment and operation lists.

e) Quality of basic amenities- stresses on the adequacy of furniture, cleanliness of the facility, and quality of food.

f) The choice of care provider means both choices within and between different Healthcare units, also opportunities to get second opinions and specialist care. Access to social support networks during care as it enhances patient welfare by integrating both, community interactions and health care activities.

g) Later, eighth element Communication was added which means the provider explains in a language the patient understands and answers the patient's questions.

Responsiveness is an intrinsic goal of the Health system. It is important due to the following reasons: Responsiveness facilitates that the information flows between the health system and the patient. Responsiveness is related to basic human rights and is a goal for all health systems. Economic, education, cultural and political systems protecting and enhancing the patients' basic human rights are the core of responsiveness. A survey conducted by WHO found that $25 \%$ of respondents felt responsiveness was an important goal of the health system (Gakidou, Murray, \& Frenk, 2000). 
Understanding responsiveness helps the provider to give better care to the patient thereby leading to better patient satisfaction. Finally, it also helps health authorities and the government to come up with policies that will respond to patient's needs and expectations in a better manner (Darby, Valentine, Murray, \& De Silva, 2000).

\subsection{Contribution to the Study}

A responsive system benefits all - the patients, the healthcare providers as well as the government.

a) Gains for Patients: Better service quality, waiting time is reduced, better and clear communication with a care provider, the staff is more courteous and hence patients' have more dignity, better basic amenities like waiting areas, water and food arrangements, cleanliness, right to choose the care provider and treatment

b) For the Hospital Management, Doctors and Staff: a Better understanding of expectations of patients, understanding of areas which are underperforming and hence need improvement, more publicity by way of mouth from satisfied customers/patients, more flow of patients and hence business, increased profitability

c) For Insurers, Employers, Corporates and the Government: Helps provide parameters to check the quality, to conduct audits, to formulate policies by the government.

Maintaining a good relationship with patients or providing good customer care is important as it has been seen that it improves the health outcome. Patients treated with attention and concern, respond better to treatment. They seek care earlier and confide in health care providers. They are also more likely to comply with medical instructions and continue using medical services (Haddad et al., 1998; Williams 1994).

A satisfied patient is likely to continue with the same provider in the long term and praise the provider to others, hence the cost of retaining customers is cheaper by approximately five times than the cost of attracting new customers. On the other hand, a dissatisfied patient is likely to change to another healthcare provider and also harm the business by negative word of mouth. Being responsive saves money, which could have been spent on solving patient complaints.

Figure 1 below gives an idea of the responsiveness concept. It shows various factors of environmental or population characteristics that directly or indirectly influence responsiveness.

Ever since the concept of responsiveness came up and World Health Organization ranked countries on basis of their performance index, there has been contentious debates on the appropriateness of undertaking international comparisons of health system performance, given that the platform of Health Systems may be quite diverse in societies with different cultural, economic or political backgrounds. Hsu et al. (2006) in their study have found that for measuring the performance of the health system, elements of responsiveness proposed by WHO should be tailored to fit the different cultural backgrounds. The issue of cross-cultural validity was raised by the World Health Organization regional offices too.

It was also proposed that when experienced responsiveness is compared internationally, the values that people attach to different aspects of the Health system should be estimated. Rottger, Blumel, Fuchs \&Busse (2014) tried finding the application of WHO responsiveness concept to chronically ill patients. Four focus groups were formed and ten themes related to responsiveness and one theme, finances, not related to responsiveness were identified. Of these eight were the same as WHO responsiveness domains and two new themes emerged namely, Trust and Coordination. Hence the study suggested that though the WHO concept of responsiveness applies to chronically ill patients it needs to be extended to include two more Domains-Trust and Coordination.

Scientific Peer Review Group (SPRG) recommended the mapping of cultural influences on responsiveness domains and also a mapping of responsiveness elements with treaties on human rights. 
Figure 1. A

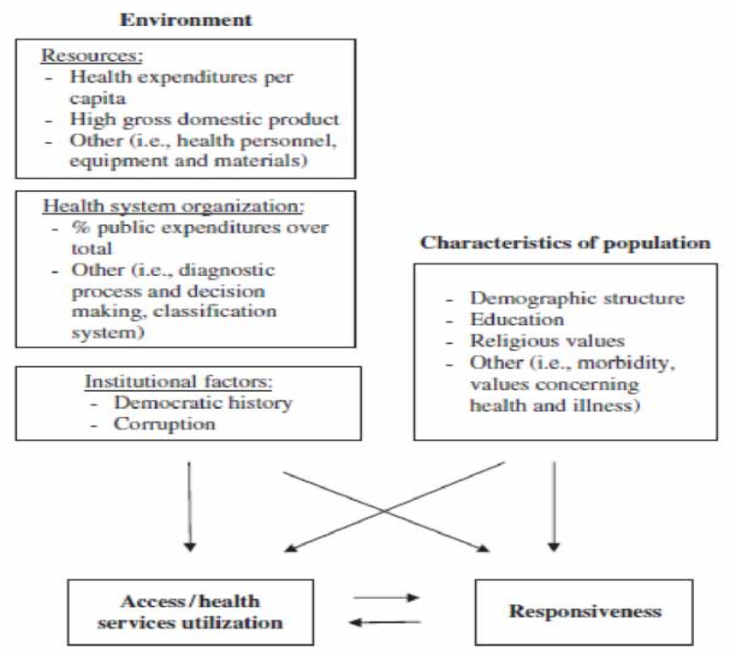

Later cross-cultural dimensions of responsiveness were reviewed and mapping of responsiveness elements to the United Nations and other treaties on human rights was done.

\subsection{Need for the Study}

In this era of consumerism and globalization, the patients are well informed of their rights and as they have global exposure their expectations have changed from the year 2000 when WHO came up with eight expectations of patients from the health system. In the current study, we have tried to find if all these eight elements of responsiveness are expected by Indian patients and are important to them. The study also established that these factors if provided lead to better patient satisfaction and hence impact customer relationships. Our study tries to identify patients' expectations from the Indian Health system which when fulfilled lead to patient satisfaction and hence are important for better customer relationship management.

In the paper, related literature review is done to identify the gaps followed by the model proposed. Further, the hypothesis was tested using Structural Equation Modeling. Based on the results, implications were drawn.

\section{LITERATURE REVIEW}

\subsection{Scenario Before World Health Organization Responsiveness Concept Came:}

All studies before the WHO Responsiveness framework were on Patients' expectations and satisfaction. The research conducted by Walt \& Gilson (1994) brought out the right to privacy expectations by patients even during childbirth. Shackly \& Ryan (1994) defined the characteristics of good patient care by researching on the best healthcare package by reviewing factors of cost and quality, comprehending the results and then deciding.

Four models about autonomy were introduced by Charles, Gafni \& Whelan (1997)

a) The paternalistic model where a health care provider takes all the decisions on behalf of the patient, as it is thought that the provider is more informed. This model is considered to be the best. 
b) The informed decision-making model is when the provider gives the information and the patient makes the decision.

c) The professional agent model when a patient willingly foregoes the right to decision making and voluntarily transfers the decision making to the provider.

d) The shared decision-making model applies when there is sharing of both information and decision making between the patient and the provider. For a consumer or patient both choices about the institution and the individual providing care are important.

The literature on patient preferences from healthcare unearthed several key factors. They included concepts such as enablement (Barratt\& Thomas, 2019; Desborough et al., 2017; Brusse \& Yen, 2013; Howie et al., 1999), length of time doctor spent in conversation with the patient which included rapport building time (Roter\& Hall, 2006; Johnson et al., 2004; Gross et al., 1988), humanness in healthcare interaction (Wensing, Weijden, \&Grol, 1998), the privacy of the patient (Trachtenbarg et al., 2017; Pankomera\& van Greunen, 2016; Cheraghi-Sohi et al., 2006; Gilson, Alilio \& Heggenhougen, 1994) $\&$ health literacy of the patient (Heuser et al., 2019; Davis, 2017; Shackly\& Ryan, 1994). The research of Howie et al., (1999) showed that longer consultation time was highly correlated with higher 'enablement' scores. Enablement score was calculated based on patient response to the following three questions related to coping with life in general as well as with illness and have a better understanding of their illness. Additionally, they were also asked, if the hospital visit increased their confidence in their health and ability to look after themselves.

Even though all these questions were considered as non-health related, as they were related to the patient getting better, they were vital. There is a high correlation with longer patient consultations as increased time duration provided greater opportunities for patients to discuss their problems. Gross \& Repka (1998) also brought out this vital element that patient's satisfaction levels were dependent on the length of time the doctor spends making conversation with the patient. An interesting finding Gross brought out was if the conversation was short and to the point explaining the results of their various tests the patients showed they were dissatisfied with their conversation. This is believed to be so as rapport building does not take place with the patient wherein the doctor directly talks about the reports the patient might not yet be in a comfort zone to share the problems. The result of the review done by authors Wensing et al., (1998) on patient priorities concerning general practice care showed that patients placed high priority for 'humaneness' in their interactions. The privacy that is provided to patients while they are being examined is another critical factor in determining whether the patients will continue to use health care services (Schwartz et al., 2015; Cheraghi-Sohi et al., 2006).

\subsection{The 2000 World Health Report}

It suggested the achievement of 3 goals of the health system as a measure of its performance. One of the goals of the health system is responsiveness which is concerned with meeting the universally legitimate expectations of patients, for example, confidentiality, prompt attention autonomy, etc. Both the average level and distribution of Responsiveness are important. Responsiveness was estimated for 191 countries and the countries were ranked based on an overall performance index calculated from scores of each domain of responsiveness. (WHO Report, 2000).

\subsubsection{The Multi-Country Survey Study (MCSS) on Health and Health System Responsiveness}

MCSS (World Health Organisation, 2005) was started by WHO in 2000-2001 to develop methods for the comparable data collection on health and health system responsiveness. It used a common instrument to assess the health of the population, the responsiveness of the health system and healthcare expenditure of households. There were some more modules on areas like adult mortality. Two types of survey operators were engaged: multi-country and a single country. 61 countries were covered in this survey. 


\subsubsection{World Health Survey}

The World Health Survey (WHS) was developed by the WHO to meet the need for reliable information. This survey was implemented in 2002-2004 in 73 countries. WHS had five modules, health system responsiveness being one of them. The other four modules were: health states of population, risk factors, coverage and access, and healthcare expenditure. Responsiveness module had more detailed questions on self-reported utilization of health services and barriers to care. Country reports on utilization, barriers to care, satisfaction and responsiveness were prepared.

\subsection{Applicability of World Health Organization Responsiveness Concept}

Hsu et al., (2006) studied and reported "The dimensions of responsiveness of a health system: A Taiwanese Perspective' in BioMed Central Public Health". The study tried to assess the applicability of seven dimensions of responsiveness proposed by the WHO namely autonomy, dignity, prompt attention, confidentiality, basic amenities, social support and choices of providers, which further evaluated the health care system of Taiwan. The study used a key informant survey and focus group research. It was concluded that to evaluate the performance of a health system, customization of elements of responsiveness as proposed by WHO is needed to suit different cultural backgrounds.

Rottger, Blumel, Fuchs\&Busse (2014) tried finding the application of WHO responsiveness concept to chronically ill patients. Four focus groups were formed and ten themes related to responsiveness and one theme, finances, not related to responsiveness were identified. Of these eight were the same as WHO responsiveness domains and two new themes emerged namely, Trust and Coordination. Hence the study suggested that though the WHO concept of responsiveness applies to chronically ill patients it needs to be extended to include two more Domains-Trust and Coordination.

Valentine, De Silva \&Murray (2000) explored the variation in importance given to various domains of responsiveness based on country-level variables- health system expenditure, geographic zones, human development, etc. and subpopulations- age, sex, health status, education, income, etc.

\subsection{Current Scenario of Responsiveness}

Ughasoro et al., (2017) examined the perceptions of patients' responsiveness to health-care services. The findings of the study revealed that the most important domain was prompt attention, dignity, and confidentiality. Whereas the choice of the health-care provider was the worst performer among the domains.

Kashkoli et al., (2017) examined the effect of hospital responsiveness on the satisfaction level of the patients. To achieve this objective, the data was collected from 500 patients of public and private hospitals operating in Tehran, Iran. Results of the regression analysis revealed that Prompt attention, Clear communication, Patient Dignity, Autonomy, Choice of care provider, Quality of basic amenities and Access to social support has a significant and positive effect on patients' satisfaction. In another study by Mohammadi et al. similar type of finding was observed where the dimensions of responsiveness have a positive effect on patients' (outpatient and inpatient) satisfaction levels (Mohammadi, Masoumi\&Kamali, 2016).

Ali, Nikoloski \& Reka (2015) analysed patient satisfaction and responsiveness to the healthcare system in Qatar. A survey was conducted in 2012 and logit analysis ordinary least squares and Probit analysis was done to find the determinants of both satisfaction and responsiveness. The study found that nationality, gender, age, and income affect the satisfaction of the public with the healthcare system.

Sajjadi, Moradi-Lakeh, Nojomi, Baradaran \& Azizi (2015) found that in Tehran the health system is not responsive to diabetic patients and the attitude of healthcare providers needs to improve. It suggested poor-performing domains of responsiveness should be given priority when activities for improvement are planned.

Malhotra \& Do (2016) assessed the relationship between the proportion of public health expenditure (PPHE) with responsiveness for the poorest individuals and the difference in responsiveness between 
the richest and poorest individuals. The study findings proved that higher PPHE was coupled with a higher probability of 'very good' responsiveness for each domain among the poorest individuals. The study suggested that to improve the responsiveness of the health system for poor patients and to decrease the inequality of responsiveness between rich and poor PPHE should be increased.

Najafi, Karami-Matin, Rezaei, Rajabi-Gilan\&Soofi (2015) conducted a study to find the responsiveness of the health system in Western Iran after the Health sector Evolution Plan (HSEP). The study found that socio-demographic variables did not affect responsiveness scores. It concluded that the overall score for each domain was better to post HSEP.

Forouzan et al., (2014) tried applying the WHO responsiveness concept to the mental health system of Tehran. Nearly half of the participants reported poor responsiveness. Autonomy, Access to care and quality of basic amenities performed badly. Finally, the study suggested that the health system should become more patient-oriented.

Forouzan et al., (2015) prepared and tested the validity and reliability of a questionnaire to check the responsiveness of the health system in Iran towards mental health patients. The questionnaire was based on the WHO concept of responsiveness and tested in clinics in Tehran.

Chao et al., (2017) evaluated the responsiveness of the health system in Jiangsu Province of China. They found the responsiveness can be improved by improving areas like the choice of care provider and prompt attention. Other suggested measures were better infrastructure, shorter waiting time. Overall the health system was found to be satisfactorily responsive.

The study conducted by Ughasoro, Okanya, Uzochukwu \& Onwujekwe (2017) assessed the responsiveness of tertiary care hospitals providing super specialty care in Nigeria after Universal Health Coverage was implemented in Nigeria. It concluded that certain domains like autonomy and choice of care provider did not perform well and need to be improved as much as the quality of basic amenities needs improvement.

\subsection{Customer Relationship Management}

Customer Relationship Management tries to understand the customers of any company through a combination of technology, people and process. Many authors have defined CRM in different ways. Blery \& Michalakopoulos, (2006) define CRM as "a strategy that helps organizations to build longterm relationships with a customer and increase profit through a proper management system and the application of customer customized approaches". Yina (2010, p. 52-55) defines CRM in healthcare as "a strategy in building the trust of the patients as well as helping patients to avoid feeling alienated in the healthcare environment and at the same time improving the service quality and efficiency of healthcare". Peppers \& Rogers, (2002) defined CRM as "one-to-one marketing that uses computer technologies to build and manage the ongoing relationship between organizations and customers. Form an organizational perspective". CRM for healthcare is a way of learning about patients, relevant communication, building good relationships, providing the right data on time, and tracking patient's results to make the necessary adjustments (Baashar et al., 2016). If there is a good relationship between hospital and patient then it will have not only positive effect on customer satisfaction but also helps in developing a better relationship between patient, physician and medical staff which ultimately lead to a better cure of the patient (Jalal et al., 2019; Grębosz-Krawczyk \&Olender, 2018; Al-Neyadi, Abdallah \& Malik, 2018; Fatima, Malik \& Shabbir, 2018; Kashkoli et al., 2017; Gandhi \& Tandon, 2017). Therefore, it is essential to identify the antecedents that affect the customer relationship in the healthcare sector. Hence, the objective of the present study is to analyse the effect of different dimensions of hospital responsiveness on customer relationships.

\section{RESEARCH METHODOLOGY:}

A comprehensive study has been conducted to understand the patient's expectations and demands. The theoretical foundation of the survey is based on secondary sources such as research papers, 
articles, magazines and articles on patient's expectations and satisfaction, for this purpose databases like EBSCO, ProQuest ware used. The study is descriptive and convenience sampling was used to collect the data. The sample size from each hospital was proportional to the number of beds in each hospital. Out of 1015 questionnaires, a total of 379 responses were received after circulation. 21 incomplete and unengaged responses were excluded from the study. Therefore, 358 responses were used for the final analysis. Samples were taken from leading private and government hospitals of Chandigarh (U.T), Panchkula (Haryana) and Mohali (Punjab). The hospital covered were PGIMER Chandigarh, Government Hospital Sector 32 Chandigarh, Fortis Hospital Mohali, IVY Mohali, MAX Mohali, Alchemist Panchkula, Government Hospital Sector 6 Panchkula. To have a representative data, the researchers have taken data from both public and private hospitals. The researchers chose Chandigarh, Panchkula, and Mohali as these represent the whole of North India and people are more educated in this area as compared to other parts of the country. Responses were collected from the patients attending O.P.D, indoor patients and the attendants of the patients.

\section{DATA ANALYSIS AND RESULTS}

To measure the proposed hypothesized relationships, the researchers first used Exploratory Factor Analysis to extract distinct factors related to the Indian Healthcare system. A questionnaire containing eight factors namely Autonomy, Communication, Confidentiality, Dignity, Prompt attention, Sound support, Quality of amenities and Choice of care provider were identified based upon standard WHO questionnaire and in-depth interviews with the patients. The reliability and validity of the questionnaire were checked. Cronbach's Alpha was used to check the reliability of the questionnaire and construct validity through CFA was used to check the validity of the questionnaire in the Indian context. The patient's responses were measured on a 5 point Likert scale anchoring 1 "Strongly disagree" to 5 "Strongly agree". Questions related to demographics, hospital visits, consultations were also included in the questionnaire. The purpose of using EFA was to check whether the items are correctly loaded on their corresponding factors and to confirm the number of factors extracted by Eigenvalues (Jhamb\& Gupta, 2016; Hair et al., 1998). A total of 21 variables ware used, which were identified from the existing researches, which resulted in eight factors accounted for $69.8 \%$ of the total variance. Further to validate the extracted factors research applied Confirmatory Factor Analysis (Gupta \& Kumar, 2017; Byrne, 2001). The results of CFA confirm that these 21 variables were loaded on their corresponding factors (latent variables) confirming the unidimensionality of the constructs and provides strong empirical confirmation of their validity.

\subsection{Measurement Model}

To test the proposed hypothesized model, we followed a two-step statistical analysis recommended by Anderson \& Gerbing (1988). In the first step, the reliability and validity of the measurement model were established and in the second step, the proposed hypothesized relationships were tested using path analysis. Results of the confirmatory factor analysis revealed an acceptable level of both reliability and validity of the measurement model. Table 1 shows that all latent variables have composite reliability value more than 0.70 , which is an indicator that present model has good reliability (Gupta, Mittal \& Mittal, 2019; Hair, Ringle, \&Sarstedt, 2011; Aggarwal, Goyal \& Nobi, 2018; Aggarwal et al., 2019; Aggarwal et al., 2020). To establish the convergent validity, we followed two steps procedure suggested by Fornell \& Larcker (1981). At the first stage, all the standardized factor loadings should be significant and greater than 0.70 . On the second stage all the factors should have equal to or more than 0.5 value of average variance extracted (AVE) and the value of composite reliability should be more than the value of AVE for that construct (Sood et al., 2019; Dhiman et al., 2018).

The results of Table 1 show that all the factors have more than 0.7 standardized factor loading. The value of AVE ranges between 0.538-0.720, which is more than the cut-off value of 0.5 (Fornell 


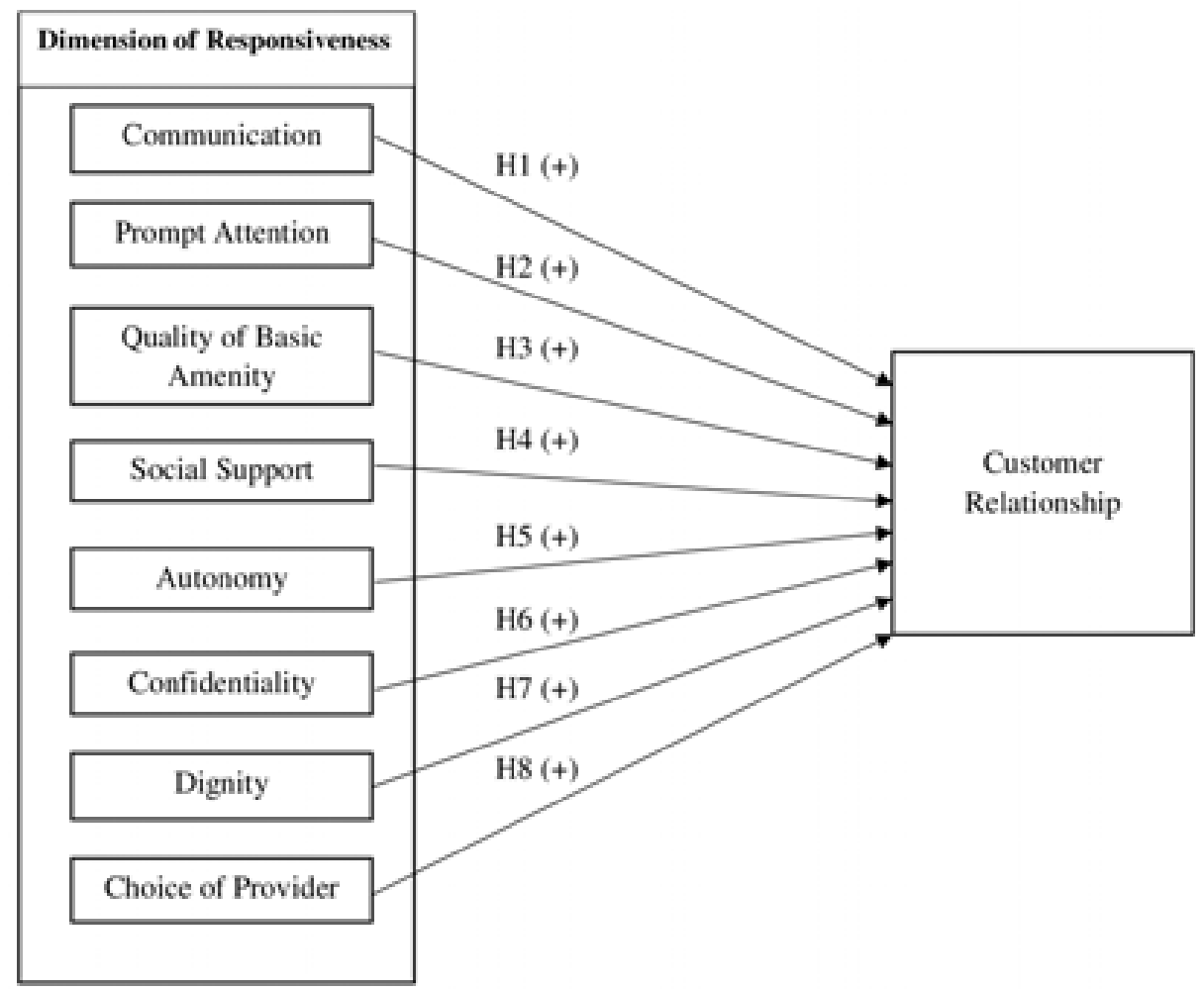

\& Larcker, 1981). Therefore, the results of table 1 showed that the measurement model had achieved convergent validity.

The results of table 2 depicted descriptive statistics and the discriminant validity of the measurement model. The result showed that the inter-construct correlation values were less than the square root of the AVE for that construct. It means that the proposed measurement model also fulfills the criterion of discriminant validity; Aggarwal, Dhaliwal \& Nobi, 2018; Dhaliwal et al., 2019; Singh et al., 2020). It means that the present model has good reliability and validity. Apart from this, results also showed that there is a positive relationship between all the latent variables.

\subsection{Structural Equation Modeling (S.E.M)}

Structural equation modeling, a multivariate technique, is employed in this research to study the relationship between patients' satisfaction and customer relationship. Arbuckle (2010), Structural Model specifies how latent variables are related to each other. The fitness of the hypothesized model was evaluated by analyzing Goodness-of-fit indices. To test the relationship between two latent constructs i.e., Patient Satisfaction (PS) and Customer Relationship (CR), various coefficient parameters were estimated as the assumptions underlying SEM are met (Mittal, Aggarwal \& Mittal, 2020; Sharma \& Gupta, 2020).

Results of table 3 depicted that effective communication has a significant and positive impact on patient-doctor relationship $(\beta=0.202, \mathrm{t}=3.737, \mathrm{p}<0.01)$. Therefore, $\mathrm{H} 1$ was accepted. Results also manifested that prompt action from the hospital to handle the patient has a significant and positive 
Table 1. Convergent Validity

\begin{tabular}{|c|c|c|c|}
\hline Factors & $\begin{array}{c}\text { Final standardized } \\
\text { loadings }\end{array}$ & $\begin{array}{l}\text { Composite construct } \\
\text { reliability }\end{array}$ & $\begin{array}{c}\text { Average variance } \\
\text { extracted }\end{array}$ \\
\hline Communication & & 0.812 & 0.592 \\
\hline COM1 & 0.724 & & \\
\hline COM2 & 0.831 & & \\
\hline COM3 & 0.749 & & \\
\hline Prompt Attention & & 0.855 & 0.598 \\
\hline PA1 & 0.718 & & \\
\hline PA2 & 0.792 & & \\
\hline PA3 & 0.851 & & \\
\hline PA4 & 0.724 & & \\
\hline Quality of Basic Amenity & & 0.77 & 0.528 \\
\hline QBA1 & 0.704 & & \\
\hline QBA2 & 0.714 & & \\
\hline QBA3 & 0.761 & & \\
\hline Social Support & & 0.806 & 0.582 \\
\hline SS1 & 0.828 & & \\
\hline SS2 & 0.715 & & \\
\hline SS3 & 0.742 & & \\
\hline Autonomy & & 0.725 & 0.569 \\
\hline AT1 & 0.719 & & \\
\hline AT2 & 0.788 & & \\
\hline Confidentiality & & 0.786 & 0.649 \\
\hline CON1 & 0.884 & & \\
\hline CON2 & 0.765 & & \\
\hline Dignity & & 0.795 & 0.662 \\
\hline DIG1 & 0.894 & & \\
\hline DIG2 & 0.724 & & \\
\hline Choice of Provider & & 0.741 & 0.59 \\
\hline $\mathrm{CH} 1$ & 0.749 & & \\
\hline $\mathrm{CH} 2$ & 0.787 & & \\
\hline
\end{tabular}

Note: Author's Compilation

impact on the patient-doctor relationship $(\beta=0.225, \mathrm{t}=4.425, \mathrm{p}<0.01)$. Hence, $\mathrm{H} 2$ was accepted. Results of the path analysis showed that there is a significant impact on the quality of basic amenities on the patient-doctor relationship $(\beta=0.185, \mathrm{t}=2.652, \mathrm{p}<0.01)$. Further, results showed that social support has a significant and positive impact on patient-doctor relationship $(\beta=0.112, \mathrm{t}=2.228, \mathrm{p}$ $<0.05)$. Hence, $\mathrm{H} 4$ was accepted. Autonomy does not have significant impact on the patient-doctor relationship $(\beta=0.072, \mathrm{t}=1.247, \mathrm{p}>0.05)$. Therefore, the $\mathrm{H} 5$ was not accepted. Results of the path analysis also revealed that confidentiality maintained by the hospital in terms of the patient disease 
Table 2. Discriminant Validity

\begin{tabular}{|l|l|l|l|l|l|l|l|l|l|l|}
\hline \multicolumn{1}{|c|}{ Factors } & M & SD & $\mathbf{1}$ & $\mathbf{2}$ & $\mathbf{3}$ & $\mathbf{4}$ & $\mathbf{5}$ & $\mathbf{6}$ & $\mathbf{7}$ & $\mathbf{8}$ \\
\hline Communication & 4.48 & 0.49 & $\mathbf{0 . 7 7}$ & & & & & & & \\
\hline Prompt Attention & 4.14 & 0.62 & 0.13 & $\mathbf{0 . 7 7}$ & & & & & & \\
\hline $\begin{array}{l}\text { Quality of basic } \\
\text { Amenity }\end{array}$ & 4.28 & 0.54 & 0.09 & 0.14 & $\mathbf{0 . 7 3}$ & & & & & \\
\hline Social Support & 3.92 & 0.55 & 0.08 & 0.34 & 0.25 & $\mathbf{0 . 7 6}$ & & & & \\
\hline Autonomy & 2.88 & 0.85 & 0.04 & 0.29 & 0.13 & 0.13 & $\mathbf{0 . 7 5}$ & & & \\
\hline Confidentiality & 4.52 & 1.10 & 0.19 & 0.22 & 0.16 & 0.14 & 0.19 & $\mathbf{0 . 8 0}$ & & \\
\hline Dignity & 3.40 & 0.47 & 0.14 & 0.11 & 0.23 & 0.15 & 0.04 & 0.24 & $\mathbf{0 . 8 1}$ & \\
\hline Choice & 4.29 & 1.19 & 0.21 & 0.22 & 0.09 & 0.16 & 0.08 & 0.13 & 0.22 & $\mathbf{0 . 7 7}$ \\
\hline
\end{tabular}

Note: The bold numbers in the diagonal are the square root of AVE

has a significant and positive impact on the patient-doctor relationship $(\beta=0.161, \mathrm{t}=2.724, \mathrm{p}<$ 0.01). Further, results also manifested that dignity has positive and significant impact on patientdoctor relationship $(\beta=0.115, \mathrm{t}=2.189, \mathrm{p}<0.05)$. In last, results depicted that there is a significant and positive impact of choice on the patient-doctor relationship $(\beta=0.168, \mathrm{t}=2.714, \mathrm{p}<0.01)$.

\section{SIGNIFICANCE OF THE STUDY}

This study adds to the knowledge pool in terms of responsiveness of the Indian Health System by filling the literature gap. It helps to understand the elements of responsiveness as an important factor in the Indian context and then prioritize these elements. Understanding responsiveness will help Health authorities to formulate new health policies which will lead to better patient satisfaction and compliance. This will help address social justice by guiding the providers to meet the legitimate expectations of patients, thereby increasing patient satisfaction and better utilization of health services. In India, it is one of the first studies that find the current status or level of responsiveness of the Indian

Table 3. Hypothesized Relationships

\begin{tabular}{|c|c|c|c|c|c|}
\hline & Relationship & Std $\beta$ & t-value & p-value & Decision \\
\hline H1 & Communication $\rightarrow$ Customer Relationship & 0.202 & 3.737 & 0.010 & Accepted \\
\hline $\mathrm{H} 2$ & Prompt Attention $\rightarrow$ Customer Relationship & 0.225 & 4.425 & 0.010 & Accepted \\
\hline H3 & $\begin{array}{l}\text { Quality of Basic Amenity } \rightarrow \text { Customer } \\
\text { Relationship }\end{array}$ & 0.185 & 2.652 & 0.010 & Accepted \\
\hline $\mathrm{H} 4$ & Social Support $\rightarrow$ Customer Relationship & 0.112 & 0.228 & 0.037 & Accepted \\
\hline H5 & $\begin{array}{l}\text { Autonomy } \rightarrow \text { Customer } \\
\text { Relationship }\end{array}$ & 0.072 & 1.247 & 0.256 & Not Accepted \\
\hline H6 & Confidentiality $\rightarrow$ Customer Relationship & 0.161 & 2.724 & 0.010 & Accepted \\
\hline $\mathrm{H} 7$ & Dignity $\rightarrow$ Customer Relationship & 0.115 & 2.189 & 0.031 & Accepted \\
\hline H8 & $\begin{array}{l}\text { Choice of Provider } \rightarrow \text { Customer } \\
\text { Relationship }\end{array}$ & 0.168 & 2.714 & 0.010 & Accepted \\
\hline
\end{tabular}

Source: Author's Compilation 
health system. It explores the importance of responsiveness elements and their application in Indian society. Another significance of the study is the collection of data from multiple sources, consumers, providers, managers. This provided depth and richness to data. It also increased the trustworthiness of findings which were similar for all the respondents. This study gives a new questionnaire to measure the responsiveness of the Indian health system which can be used for future studies.

Hence this study can be considered as an important step to identify areas which are performing well and areas that need improvement to give patients a more responsive health system. The study will be of National interest with wider appeal to a broader audience and will provide interest in other researchers to conduct similar studies in their regions. A most important contribution of the study was the development of the Responsiveness measurement questionnaire according to Indian needs which can be used to study and measure the responsiveness of the Indian health system.

\subsection{Significance for Policy Makers}

The results of the study indicate that autonomy, quality of basic amenities, communication and choice of care provider are the most important elements to the patient. Hence policies should be made to ensure that the patients are provided good basic amenities like well-ventilated waiting rooms, cleanliness, potable water, good nutritious food. Also, they should be given the right to choose the care provider and to decide their treatment. The doctors should explain the disease and its treatment in a language that the patients understand and should answer their queries to satisfy them.

\section{LIMITATIONS AND FUTURE SCOPE OF THE STUDY}

\subsection{Limitations}

Since the study was conducted in two districts and one Union territory of Northern India transferability of its results to the whole of India has to be explored. Secondly, only two new elements were shortlisted and tested for their importance to Indian patients and then inclusion into responsiveness. There may be several other elements like medical ethics, trust, and coordination between caretakers and others which may be on the expectation list of patients in India and need to be tested on importance scale and then may be added to existing responsiveness elements.

Another limitation is that only one methodology of data collection through questionnaire was used as per WHO protocol but to add depth and more insight into patients' psychology qualitative methods like Focus Group discussions (FGDs) can be conducted. This would help record actual interactions between the consumers and providers of healthcare.

The questionnaire used was shortened in consultation with experts from the field and its reliability and validity tested through a pilot study. This was done to capture the correct responses keeping in mind the attention span of respondents. Adding vignettes could have added better responses as was done in the WHO questionnaire used for WHS.

\subsection{Future Research}

The study of responsiveness offers a lot of opportunities in a variety of areas for future researchers. Researchers may study:

- Similar studies at country level to find overall responsiveness of the Indian Health system and if there are any differences region wise

- Whether there are other elements besides those confirmed by this study which is important to Indians and should be included in responsiveness

- Studies to find responsiveness to different vulnerable groups that are usually discriminated, for example, HIV/AIDS patients, disabled.

- Responsiveness of health system to hearing impaired, visually impaired or intellectually impaired 
- Comparison of the responsiveness of health providers in the public vs the private sector, or the non-government sector.

- The relative importance of various elements of responsiveness can also be studied based on patients' perceptions.

- Rankings of district health systems on responsiveness can be done after district-level surveys. These rankings can become a useful indicator of health system performance.

- Longitudinal studies to see responsiveness changes over some time will be very important to the hospital sector

The study findings indicate that a lot needs to be explored and future research will help better understand the responsiveness process and also improve the quality of healthcare services. 


\section{REFERENCES}

Aggarwal, A., Chand, P. A., Jhamb, D., \& Mittal, A. (2020). Leader-Member Exchange, Work Engagement and Psychological Withdrawal Behaviour: The Mediating Role of Psychological Empowerment. Frontiers in Psychology, 11, 1-17. doi:10.3389/fpsyg.2020.00423 PMID:32296361

Aggarwal, A., Dhaliwal, R. S., \& Nobi, K. (2018). Impact of structural empowerment on organizational commitment: The mediating role of women's psychological empowerment. Vision (Basel), 22(3), 284-294. doi: $10.1177 / 0972262918786049$

Aggarwal, A., Goyal, J., \& Nobi, K. (2018). Examining the Impact of Leader-Member Exchange on Perceptions of Organizational Justice: The Mediating Role of Perceptions of Organizational Politics. Theoretical Economics Letters, 8(11), 2308-2329. doi:10.4236/tel.2018.811150

Aggarwal, A., Mittal, R., Gupta, S., \& Mittal, A. (2019). Internet of Things Driven Perceived Value Co-Creation in Smart Cities of the Future: A PLS-SEM Based Predictive Model. Journal of Computational and Theoretical Nanoscience, 16(9), 4053-4058. doi:10.1166/jctn.2019.8292

Al-Neyadi, H. S., Abdallah, S., \& Malik, M. (2018). Measuring patient's satisfaction of healthcare services in the UAE hospitals: Using SERVQUAL. International Journal of Healthcare Management, 11(2), 96-105. doi $: 10.1080 / 20479700.2016 .1266804$

Ali, F. M. H., Nikoloski, Z., \& Reka, H. (2015). Satisfaction and responsiveness with health-care services in Qatar-Evidence from a survey. Health Policy (Amsterdam), 119(11), 1499-1505. doi:10.1016/j. healthpol.2015.09.012 PMID:26511059

Baashar, Y. M., Mahomood, A. K., Almomani, M. A., \& Alkawsi, G. A. (2016, August). Customer relationship management (CRM) in a healthcare organization: A review of ten years of research. In $20163 \mathrm{rd}$ International Conference on Computer and Information Sciences (ICCOINS) (pp. 97-102). IEEE.

Barratt, J., \& Thomas, N. (2019). Nurse practitioner consultations in primary health care: A case study-based survey of patients' pre-consultation expectations, and post-consultation satisfaction and enablement. Primary Health Care Research and Development, 20, 20. doi:10.1017/S1463423618000415 PMID:30012232

Blery, E. K., \& Michalakopoulos, M. G. (2006). An e-CRM application in the telecommunications sector: A case study from Greece. EuroMed Journal of Business, 1(2), 5-14. doi:10.1108/14502190610750135

Brusse, C. J., \& Yen, L. E. (2013). Preferences, predictions and patient enablement: A preliminary study. BMC Family Practice, 14(1), 116. doi:10.1186/1471-2296-14-116 PMID:23941606

Carr-Hill, R. A. (1992). The measurement of patient satisfaction. Journal of Public Health, 14(3), 236-249. PMID:1419201

Chao, J., Lu, B., Zhang, H., Zhu, L., Jin, H., \& Liu, P. (2017). Healthcare system responsiveness in Jiangsu Province, China. BMC Health Services Research, 17(1), 31. doi:10.1186/s12913-017-1980-2 PMID:28086950

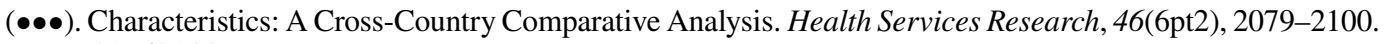
PMID:21762144

Charles, C., Gafni, A., \& Whelan, T. (1997). Shared decision-making in the medical encounter: What does it mean?(or it takes at least two to tango). Social Science \& Medicine, 44(5), 681-692. doi:10.1016/S02779536(96)00221-3 PMID:9032835

Cheraghi-Sohi, S., Bower, P., Mead, N., McDonald, R., Whalley, D., \& Roland, M. (2006). What are the key attributes of primary care for patients? Building a conceptual 'mapof patient preferences. Health Expectations, 9(3), 275-284. doi:10.1111/j.1369-7625.2006.00395.x PMID:16911142

Davis, J. (2017). Engage2: Implementing a health literacy protocol for patient assessment and engagement. Journal of Consumer Health on the Internet, 21(4), 338-349. doi:10.1080/15398285.2017.1361278

De Silva, A., \& Valentine, N. (2000). Measuring responsiveness: results of a key informants survey in 35 countries. World Health Organization. 
Desborough, J., Banfield, M., Phillips, C., \& Mills, J. (2017). The process of patient enablement in general practice nurse consultations: A grounded theory study. Journal of Advanced Nursing, 73(5), 1085-1096. doi:10.1111/ jan.13199 PMID:27809374

Dhaliwal, M. S., Mittal, A., Aggarwal, A., \& Chand, P. K. (2019). Determining the Factors Affecting the Selection of Private Universities and Colleges in Indian Context: A Structural Equation Modeling Approach. Journal of Advanced Research in Dynamical \& Control Systems, 11(8), 2579-2590.

Dhiman, R., Chand, P. K., \& Gupta, S. (2018). Behavioural Aspects Influencing Decision to Purchase Apparels amongst Young Indian Consumers. FIIB Business Review, 7(3), 188-200. doi:10.1177/2319714518790308

Fatima, T., Malik, S. A., \& Shabbir, A. (2018). Hospital healthcare service quality, patient satisfaction and loyalty. International Journal of Quality \& Reliability Management, 35(6), 1195-1214. doi:10.1108/ IJQRM-02-2017-0031

Forouzan, A. S., Rafiey, H., Padyab, M., Ghazinour, M., Dejman, M., \& Sebastian, M. S. (2014). Reliability and validity of a mental health system responsiveness questionnaire in Iran. Global Health Action, 7(1), 24748. doi:10.3402/gha.v7.24748 PMID:25079288

Forouzan, S., Padyab, M., Rafiey, H., Ghazinour, M., Dejman, M., \& San Sebastian, M. (2015). Measuring the Mental health-care system responsiveness: Results of an Outpatient survey in Tehran. Frontiers in Public Health, 3, 285. PMID:26858944

Gakidou, E., Murray, C. J., \& Frenk, J. (2000). Measuring preferences on health system performance assessment. World Health Organization.

Gandhi, P., \& Tandon, N. (2017). Study to analyze the variables that affect CRM implementation in the Hospitals. Advances in Computational Sciences and Technology, 10(5), 933-944.

Gilson, L., Alilio, M., \& Heggenhougen, K. (1994). Community satisfaction with primary health care services: An evaluation undertaken in the Morogoro region of Tanzania. Social Science \& Medicine, 39(6), 767-780. doi:10.1016/0277-9536(94)90038-8 PMID:7973873

Gostin, L., Hodge, J. G., Valentine, N., \& Nygren-Krug, H. (2002). The domains of health responsiveness: A human rights assessment. Health and Human Rights Working Paper Series, (2), 1-24.

Grębosz-Krawczyk, M., \& Olender, M. (2018). The application of mobile marketing in CRM in the medical sector. Handel Wewnętrzny, (3 (374)), 162-171.

Gross, M. R., \& Repka, J. (1998). Stability with inheritance in the conditional strategy. Journal of Theoretical Biology, 192(4), 445-453. doi:10.1006/jtbi.1998.0665 PMID:9782102

Gross, M. R., \& Repka, J. (1998). Stability with inheritance in the conditional strategy. Journal of Theoretical Biology, 192(4), 445-453. doi:10.1006/jtbi.1998.0665 PMID:9782102

Gupta, S., \& Kumar, R. (2017). Effectiveness of Digital Marketing A Descriptive Analysis. International Journal of Applied Business and Economic Research, 15, 1-8.

Gupta, S., Mittal, R., \& Mittal, A. (2019). Modelling the Intentions to Adopt UPIs: A PLSSEM Approach. In 2019 6th International Conference on Computing for Sustainable Global Development (INDIACom) (pp. 246250). IEEE.

Haddad, S., Fournier, P., \&Potvin, L. (1998). Measuring lay people's perceptions of the quality of primary health care services in developing countries. Validation of a 20 -item scale. Academic Press.

Heuser, C., Diekmann, A., Kowalski, C., Enders, A., Conrad, R., Pfaff, H., Ansmann, L., \& Ernstmann, N. (2019). Health literacy and patient participation in multidisciplinary tumour conferences in breast cancer care: A multilevel modelling approach. BMC Cancer, 19(1), 330. doi:10.1186/s12885-019-5546-z PMID:30961598

Howie, J. G. R., Heaney, D. J., Maxwell, M., Walker, J. J., Freeman, G. K., \& Rai, H. (1999). Quality at general practice consultations: A cross-sectional survey. British Medical Journal, 319(7212), 738-743. doi:10.1136/ bmj.319.7212.738

Hsu, C. C., Chen, L., Hu, Y. W., Yip, W., \& Shu, C. C. (2006). The dimensions of responsiveness of a health system: A Taiwanese perspective. BMC Public Health, 6(1), 72. doi:10.1186/1471-2458-6-72 PMID:16542462 
Jalal, A. N., Bahari, M., Tarofder, A. K., \& Musa, W. M. N. M. W. (2019). Factors influencing Customer Social Relationship Management implementation and its benefits in the healthcare industry. Polish Journal of Management Studies, 19.

Jhamb, D., \& Gupta, M. S. (2016). Antecedents of Online Shopping Attractiveness: The Youngster Perspective. Global Journal of Management and Business Research.

Johnson, R. L., Roter, D., Powe, N. R., \& Cooper, L. A. (2004). Patient race/ethnicity and quality of patientphysician communication during medical visits. American Journal of Public Health, 94(12), 2084-2090. doi:10.2105/AJPH.94.12.2084 PMID:15569958

Kashkoli, S. A., Zarei, E., Daneshkohan, A., \& Khodakarim, S. (2017). Hospital responsiveness and its effect on overall patient satisfaction. International Journal of Health Care Quality Assurance, 30(8), 728-736. doi:10.1108/ IJHCQA-07-2016-0098 PMID:28958198

Malhotra, C., \& Do, Y. K. (2016). Public health expenditure and health system responsiveness for low-income individuals: Results from 63 countries. Health Policy and Planning, 32(3), 314319. doi:10.1093/heapol/czw127 PMID:27651279

Mittal, A., Aggarwal, A., \& Mittal, R. (2020). Predicting University Students' adoption of Mobile News Applications. International Journal of E-Services and Mobile Applications.

Mohammadi, A., Masoumi, J. H., \& Kamali, K. (2016). Patients' satisfaction in Zanjan educational hospitals and their relationship with responsiveness. Journal of Human, Environment, and Health Promotion, 1(4), 227-236. doi:10.29252/jhehp.1.4.227

Murray, C. J., \& Frenk, J. (2000). A framework for assessing the performance of health systems. Bulletin of the World Health Organization, 78(6), 717-731. PMID:10916909

Murray, C. J., Gakidou, E. E., \& Frenk, J. (1999). Health inequalities and social group differences: What should we measure? Bulletin of the World Health Organization, 77(7), 537. PMID:10444876

Najafi, F., Karami-Matin, B., Rezaei, S., Rajabi-Gilan, N., \& Soofi, M. (2016). Health system responsiveness after health sector evolution plan (HSEP): An inpatient survey in Kermanshah in 2015. Medical Journal of the Islamic Republic of Iran, 30, 387. PMID:27493931

Owens, D. J., \& Batchelor, C. (1996). Patient satisfaction and the elderly. Social Science \& Medicine, 42(11), 1483-1491. doi:10.1016/0277-9536(95)00234-0 PMID:8771631

Pankomera, R., \& van Greunen, D. (2016, May). Privacy and security issues for a patient-centric approach in public healthcare in a resource-constrained setting. In 2016 IST-Africa Week Conference. IEEE.

Peppers, D., \& Rogers, M. (2002). The one to one manager: Real-world lessons in customer relationship management. Crown Pub.

Robone, S., Rice, N., \& Smith, P. C. (2011). Health systems' responsiveness and its characteristics: A cross-country comparative analysis. Health Services Research, 46(6pt2), 2079-2100. doi:10.1111/j.1475-6773.2011.01291.x PMID:21762144

Roter, D., \& Hall, J. A. (2006). Doctors talking with patients/patients talking with doctors: improving communication in medical visits. Greenwood Publishing Group.

Röttger, J., Blümel, M., Fuchs, S., \& Busse, R. (2014). Assessing the responsiveness of chronic disease care-Is the World Health Organization's concept of health system responsiveness applicable? Social Science \& Medicine, 113, 87-94. doi:10.1016/j.socscimed.2014.05.009 PMID:24852659

Sajjadi, F., Moradi-Lakeh, M., Nojomi, M., Baradaran, H. R., \& Azizi, F. (2015). Health system responsiveness for outpatient care in people with Diabetes Mellitus in Tehran. Medical Journal of the Islamic Republic of Iran, 29, 293. PMID:26913256

Schwartz, P. H., Caine, K., Alpert, S. A., Meslin, E. M., Carroll, A. E., \& Tierney, W. M. (2015). Patient preferences in controlling access to their electronic health records: A prospective cohort study in primary care. Journal of General Internal Medicine, 30(1), 25-30. doi:10.1007/s11606-014-3054-z PMID:25480721 
Shackley, P., \& Ryan, M. (1994). What is the role of the consumer in health care? Journal of Social Policy, 23(4), 517-541. doi:10.1017/S0047279400023333

Sharma, G., \& Gupta, S. (2020). Modelling the impact of corporate sustainability on economic performance with reference to Indian financial industry. World Review of Entrepreneurship, Management and Sustainable Development, 16(3), 317-328. doi:10.1504/WREMSD.2020.107272

Singh, J., Chand, P., Mittal, A., \& Aggarwal, A. (2020). High-performance work system and organizational citizenship behaviour at the shop floor. Benchmarking: An International Journal. doi:10.1108/BIJ-07-2019-0339

Sitzia, J., \& Wood, N. (1997). Patient satisfaction: A review of issues and concepts. Social Science \& Medicine, 45(12), 1829-1843. doi:10.1016/S0277-9536(97)00128-7 PMID:9447632

Sood, M., Sharma, B., Gupta, S., Dawra, S., \& Kaushik, C. (2019). Modelling the Factors Responsible for Better Health Service Quality: Perception of Service Providers. Indian Journal of Public Health Research \& Development, 10(9), 408-413. doi:10.5958/0976-5506.2019.02461.6

Trachtenbarg, D. E., Asche, C., Ramsahai, S., Duling, J., \& Ren, J. (2017). The benefits, risks and costs of privacy: Patient preferences and willingness to pay. Current Medical Research and Opinion, 33(5), 845-851. doi:10.1080/03007995.2017.1292229 PMID:28166481

Ughasoro, M. D., Okanya, O. C., Uzochukwu, B. S. C., \& Onwujekwe, O. E. (2017). An exploratory study of patients' perceptions of responsiveness of tertiary health-care services in Southeast Nigeria: A hospital-based cross-sectional study. Nigerian Journal of Clinical Practice, 20(3), 267-273. doi:10.4103/1119-3077.183255 PMID:28256478

Ughasoro, M. D., Okanya, O. C., Uzochukwu, B. S. C., \&Onwujekwe, O. E. (2017). An exploratory study of patients' perceptions of responsiveness of tertiary healthcare services in Southeast Nigeria: A hospital-based cross-sectional study. Academic Press.

Valentine, N., De Silva, A., \& Murray, C. (2000). Estimating responsiveness level and distribution for 191 countries: methods and results. World Health Organization.

Valentine, N. B., de Silva, A., Kawabata, K., Darby, C., Murray, C. J., \& Evans, D. B. (2003). Health system responsiveness: concepts, domains and operationalization. Health systems performance assessment: debates, methods and empiricism. World Health Organization.

Walt, G., \& Gilson, L. (1994). Reforming the health sector in developing countries: The central role of policy analysis. Health Policy and Planning, 9(4), 353-370. doi:10.1093/heapol/9.4.353 PMID:10139469

Wensing, M., van der Weijden, T., \& Grol, R. (1998). Implementing guidelines and innovations in general practice: Which interventions are effective? The British Journal of General Practice, 48(427), 991-997. PMID:9624774

WHO Expert Committee on Malaria \& World Health Organization. (2000). WHO expert committee on malaria: twentieth report (No. 892). World Health Organization.

Williams, B. (1994). Patient satisfaction: A valid concept? Social Science \& Medicine, 38(4), 509-516. doi:10.1016/0277-9536(94)90247-X PMID:8184314 